\title{
Induction of c-fos Expression in Hypothalamic Magnocellular Neurons Requires Synaptic Activation and Not Simply Increased Spike Activity
}

\author{
Simon M. Luckman, ${ }^{1}$ Richard E. J. Dyball, ${ }^{2}$ and Gareth Leng ${ }^{1}$ \\ 'Department of Neurobiology, AFRC Babraham Institute, Babraham, Cambridge, CB2 4AT, United Kingdom and \\ ${ }^{2}$ Department of Anatomy, University of Cambridge, Cambridge, CB2 3DY, United Kingdom
}

\begin{abstract}
Magnocellular neurons of the hypothalamic supraoptic nucleus have been shown to express the immediate-early gene c-fos in a number of experimental and physiological circumstances. In each case the induction of the immediate-early gene followed the increase in the spike activity of the cells. Since an increase in the intracellular concentration of calcium following influx through voltage-sensitive calcium channels is a known stimulus for $c$-fos expression and since the action potentials of these neurons have a large calcium component, we hypothesized that $c$-fos induction in these neurons could be attributed to calcium influx during spike activity. In the present experiments we use extracellular recording and immunocytochemistry for Fos, the protein product of c-fos, to demonstrate the activation of the cells following intracerebroventricular administration of the muscarinic agonist, carbachol. Fos expression following carbachol injection was then compared with that induced by a similar number of antidromically evoked action potentials. Antidromic activation, unlike the activation induced by carbachol, did not lead to the induction of Fos. We conclude that Fos induction in these neurons requires receptor activation rather than spike activity.
\end{abstract}

[Key words: immediate-early genes, c-fos, magnocellular neurons, carbachol, spike activity, intracellular calcium]

Immediate-early gene (IEG) expression has been extensively uscd as a tool for the functional mapping of neuronal activation (Morgan and Curran, 1991; Hoffman et al., 1993), though the mechanism by which it is initiated and the consequence for the neurons remains, in the majority of circumstances, unknown. Using in situ hybridization for c-fos or immunocytochemistry for its protein product, Fos, hypothalamic magnocellular vasopressin and oxytocin neurons have been shown to be stimulated in a number of physiological and experimental circumstances (Giovanelli et al., 1990; Hamamura et al., 1991, 1992; Sharp et al., 1991; Verbalis et al., 1991; Shen et al., 1992; Luckman et al, 1993) each of which is associated with an increased spike frequency of the neurons. In the case of salt-loading or water deprivation, the neuronal firing rate increases progres-

\footnotetext{
Received Aug. 30, 1993; revised Jan. 20, 1994; accepted Feb. 8, 1994.

We thank Drs. G. I. Evan and D. Hancock for their kind gift of the Fos antibody, and Dr. R. J. Bicknell for commenting on the manuscript. This work was supported by an AFRC Link Grant.

Correspondence should be addressed to Dr. S. M. Luckman at the above address Copyright (C) 1994 Society for Neuroscience $0270-6474 / 94 / 144825-06 \$ 05.00 / 0$
}

sively as the plasma osmolarity is elevated. This response is dependent upon inputs from forebrain structures associated with the lamina terminalis; although both vasopressin and oxytocin neurons are osmoreceptive, synaptic input is necessary for full activation of the secretory cells (Bourque, 1989; Leng et al., 1992). C-fos is also induced in oxytocin neurons by intravenous administration of cholecystokinin (Verbalis et al., 1991). A single injection of CCK produces a transient activation of oxytocin, but not vasopressin neurons, that increases their firing rate by only 1-2 spikes/sec for about 15 min (Renaud et al:, 1987; Leng, 1991). A projection from the brainstem appears to be critical for the CCK response (Luckman, 1992; Leng et al., 1993a). By contrast, another well-characterized stimulus for oxytocin release, suckling, does not appear to be a stimulus for c-fos induction since no Fos is seen in the supraoptic nucleus of the lactating rat (Fenelon et al., 1993). We have observed that this is probably not due to trans inhibition of IEGs on their own production (Sassone-Corsi et al., 1988) since the removal of pups, even when newly born, and their subsequent reuniting with their mother to produce an acute stimulus for oxytocin secretion, does not result in the expression of $\mathrm{c}-f o s, \mathrm{c}-j u n$, or their protein products, Fos and Jun (S. M. Luckman, unpublished observations). However, c-fos can be induced in the sodium pentobarbitone anesthetized lactating rat by intraperitoneal hypertonic saline injection. Although the suckling stimulus is continuous in the rat, oxytocin neurons show short highfrequency bursts of activity followed by silent periods (Poulain and Wakerley, 1982) and therefore there is very little overall increase in oxytocin neuronal fring during lactation. Thus, either the pattern of activity during lactation is not suitable for the induction of c-fos or an appropriate synaptically driven mechanism is not operating.

C-fos transcription can be induced in cells by a number of second messenger systems, including an increased concentration of intracellular calcium following membrane depolarization and influx through voltage-dependent calcium channels (Sheng et al., 1990). As oxytocin and vasopressin neurons are known to have an important calcium component to their action potentials (Renaud, 1987), we hypothesized that spike activity itself rather than synaptic input might be responsible for $c$-fos expression in these and perhaps other neurons. In order to assess this hypothesis we first needed to define an experimental stimulus that activated magnocellular neurons by a receptor-mcdiatcd action and to monitor this activation by both electrophysiology and Fos immunocytochemistry. Having established an experimental stimulus which produced a reproducible response, a similar level 

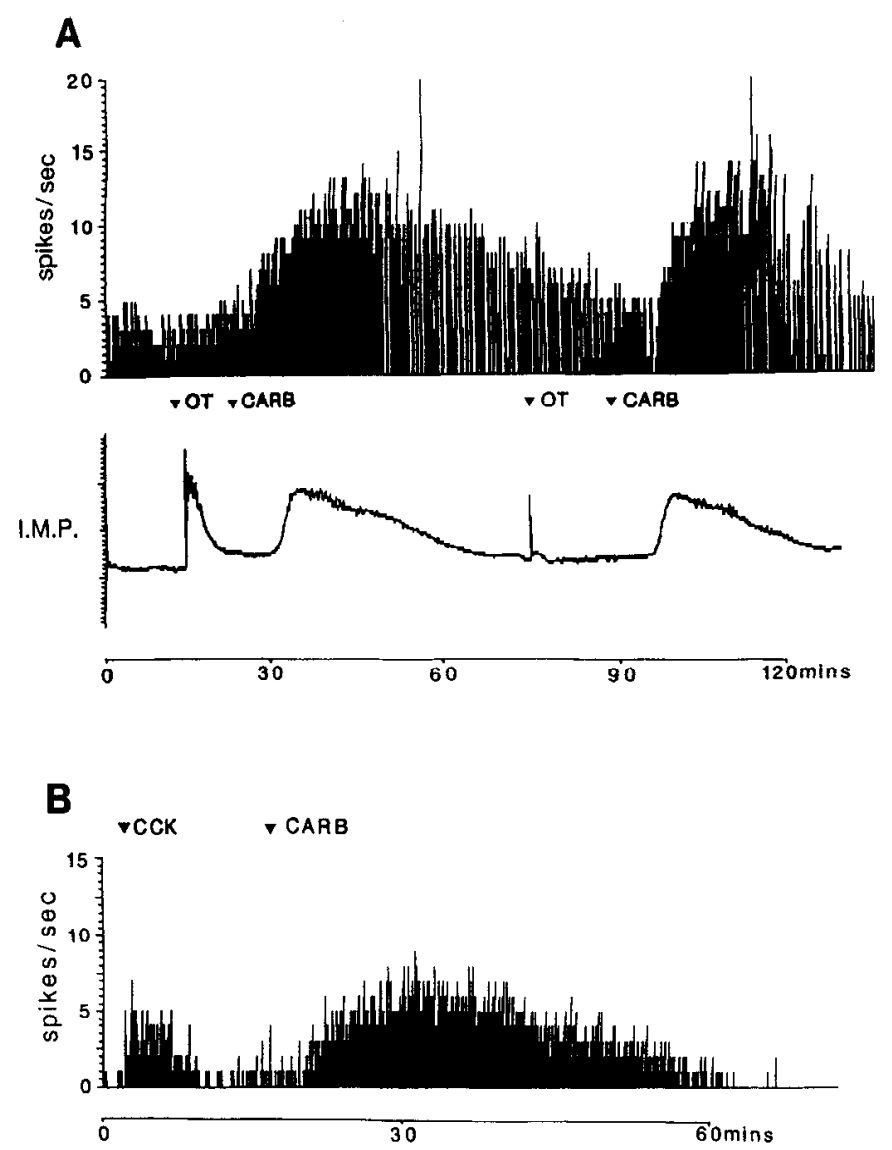

Figure 1. A, The effect of intracerebroventricular carbachol on intramammary pressure (I.M.P., bottom panel) and spike activity of a supraoptic neuron (top panel). The sensitivity of the mammary gland was checked by injection of two doses of oxytocin intravenously $(O T$; first dose $1 \mathrm{mU}$, second dose $0.25 \mathrm{mU}$ ). The I.M.P. trace, which is on an arbitrary scale, shows a response to two injections of carbachol (CARB both $0.2 \mu \mathrm{g}$, i.c.v.). The top panel shows the spike activity of a neuron in the supraoptic nucleus recorded at the same time. This neuron was antidromically identified as projecting to the pituitary and to be vasopressinergic due to its phasic pattern of firing and the fact that it did not respond to a subsequent injection of CCK $(20 \mu \mathrm{g} / \mathrm{kg}$, i.v. $) . B$, The response of a supraoptic oxytocin neuron to intracerebroventricular carbachol. This antidromically identified supraoptic neuron was shown to be oxytocinergic by its response to a single injection of CCK $(20 \mu \mathrm{g} /$ $\mathrm{kg}$, i.v.). The neuron was later activated by carbachol (CARB; $0.2 \mu \mathrm{g}$, i.c.v.).

of spike activity was induced in the magnocellular neurons by antidromic stimulation. Such stimulation leads to spike activity in these neurons, without the influence of synaptic input.

The muscarinic receptor agonist, carbachol, is known to evoke both vasopressin and oxytocin release (Iitake et al., 1986; Clarke et al., 1978), and a recent report has shown that other muscarinic receptor agonists given systemically lead to Fos induction throughout the supraoptic nucleus (Hughes and Dragunow, 1993). Here we use the pentobarbitone anesthetized lactating rat to assess the response of magnocellular neurons to intracerebroventricular (i.c.v.) carbachol and antidromic stimulation. This model is particularly suitable since the correct placement of the injection needle in the ventricle or the stimulating electrode on the pituitary stalk can be immediatcly validated by recording an increase in intramammary pressure subsequent to oxytocin release. Thus. the induction of c-fos due to surgery is minimized.

\section{Materials and Methods}

Animals and general surgery. Lactating Wistar rats from the Babraham colony were kept, with their litters, under a $14 \mathrm{hr}$ light/10 hr dark lighting regime and with food and water freely available. Rats in the 7 th- 9 th day of lactation were anesthetized with sodium pentobarbitone $(60 \mathrm{mg} /$ kg i.p.; Sagatal, May and Baker Ltd., UK) and given supplementary doses of anesthetic during surgery. A mammary gland and jugular vein were cannulated in each rat to allow the measurement of intramammary pressure and the injection of oxytocin intravenously (i.v.), respectively. Mammary gland responsiveness was checked with single injections of 0.25-1 mU of oxytocin (Syntocinon, Sandoz Pharmaceuticals, UK). For cranial surgery, the rats were positioned in a stereotaxic frame with the dorsal surface of the skull placed horizontally so that coordinates corresponded to the atlas of Paxinos and Watson (1986). I.c.v. injections were made into the lateral ventricle, $2 \mathrm{~mm}$ lateral to midline, $3 \mathrm{~mm}$ posterior to bregma, and $4.5 \mathrm{~mm}$ below the surface of the skull. Correct placement of the injection needle was demonstrated by increased intramammary pressure following carbachol injection $(0.2 \mu \mathrm{g}$ of carbamylcholine chloride in $2 \mu \mathrm{l}$ of isotonic saline; Sigma Chemicals, UK).

Experiments with i.c.v. carbachol. For the purposes of antidromic identification, a concentric bipolar stimulating electrode (type SNE 100, Clark Electromedical Instruments, UK) was lowered onto the distal pituitary stalk. The electrode was positioned by reference to a littermate of the experimental animal which was placed in the stereotaxic frame immediately before the experiment. The correct placement of the stimulating electrode was verified in each experimental animal by an increase in intramammary pressure following a short stimulus train $(3 \mathrm{sec}, 50$ $\mathrm{H} 7$ ). A $0.9 \% \mathrm{NaCl}$-filled micropipette was lowered into the region of the supraoptic nucleus to allow single unit extracellular recording of neurons $(1.8 \mathrm{~mm}$ lateral to midline, $0.5 \mathrm{~mm}$ posterior to bregma, $9 \mathrm{~mm}$ below the surface of the brain). Magnocellular neurons were identified as projecting to the pituitary by antidromic activation and as putative oxytocin or vasopressin neurons by their firing pattern and their response to a single i.v. injection of chulecystokinin $(20 \mu \mathrm{g} / \mathrm{kg}$ body weight, CCK-8 sulfated; Sigma). Oxytocin neurons respond to CCK with continuous firing at a transiently increased rate. Vasopressin neurons tend to fire phasically and they either do not respond to CCK or are briefly inhibited (Leng et al., 1991). The responses of both oxytocin and vasopressin neurones to single or double i.c.v. injections of carbachol $(0.2$ $\mu \mathrm{g}$ in $2 \mu \mathrm{l}$ ) were assessed.

Another group of anesthetized lactating rats was used for studying the effects of i.c.v. carbachol on the expression of Fos-like immunoreactivity (Fos-LI). Two injections of carbachol $(0.2 \mu \mathrm{g}$ in $2 \mu$ l, i.c.v.) were given separated by a $20 \mathrm{~min}$ period. Control animals were given injections of the same volume of isotonic saline. Ninety minutes after the second injection the animals were perfused transcardially with heparinized saline followed by $4 \%$ paraformaldehyde in $0.1 \mathrm{~m}$ phosphate buffer. The brains were cryoprotected by immersion in $30 \%$ buffered sucrose before being frozen on dry ice and stored at $-80^{\circ} \mathrm{C} ; 40 \mu \mathrm{m}$ sections were cut on a freezing sledge microtome. Standard immunocytochemistry was carried out on free-floating sections using a polyclonal antibody raised in the rabbit against the $\mathrm{N}$-terminus of the human Fos peptide. This antibody has been previously characterized (Hunt et al., 1987). Fos-LI was visualized by sequential incubation in peroxidaselabeled anti-rabbit IgG (Vector Labs, UK) and nickel intensified diaminobenzidine (adapted from Shu et al., 1988). Sections were mounted on gelatinized glass slides to allow counting of the number of Fos-LI positive nuclear profiles per section. This figure was taken for each animal and meaned to give a value for each experimental group. Groups were compared statistically using a two-tailed Mann-Whitney $U$ test.

Antidromic stimulation of magnocellular neurons. Lactating rats were prepared as before with a stimulating electrode on the pituitary stalk and its placement assessed with a short stimulus train that produced a mammary response equivalent to a bolus injection of oxytocin $(0.25-$ $1 \mathrm{mU}$, i.v.). Animals that did not show a full mammary response were not used in these experiments. In order to mimic the maximum electrical activity elicited by the two injections of carbachol in any of the supraoptic neurons recorded extracellularly, the axons of the magnocellular neurons projecting to the pituitary were stimulated at $15 \mathrm{~Hz}$ for two periods of $15 \mathrm{~min}$, separated by a $5 \mathrm{~min}$ period. Stimulation consisted of biphasic pulses of $1 \mathrm{~mA}$ peak to peak and with a duration of $1 \mathrm{msec}$. Ninety minutes after the start of the second period of electrical stimulation the rats were perfused and the brains treated for Fos immunocytochemistry as described above. In control animals, the stim- 

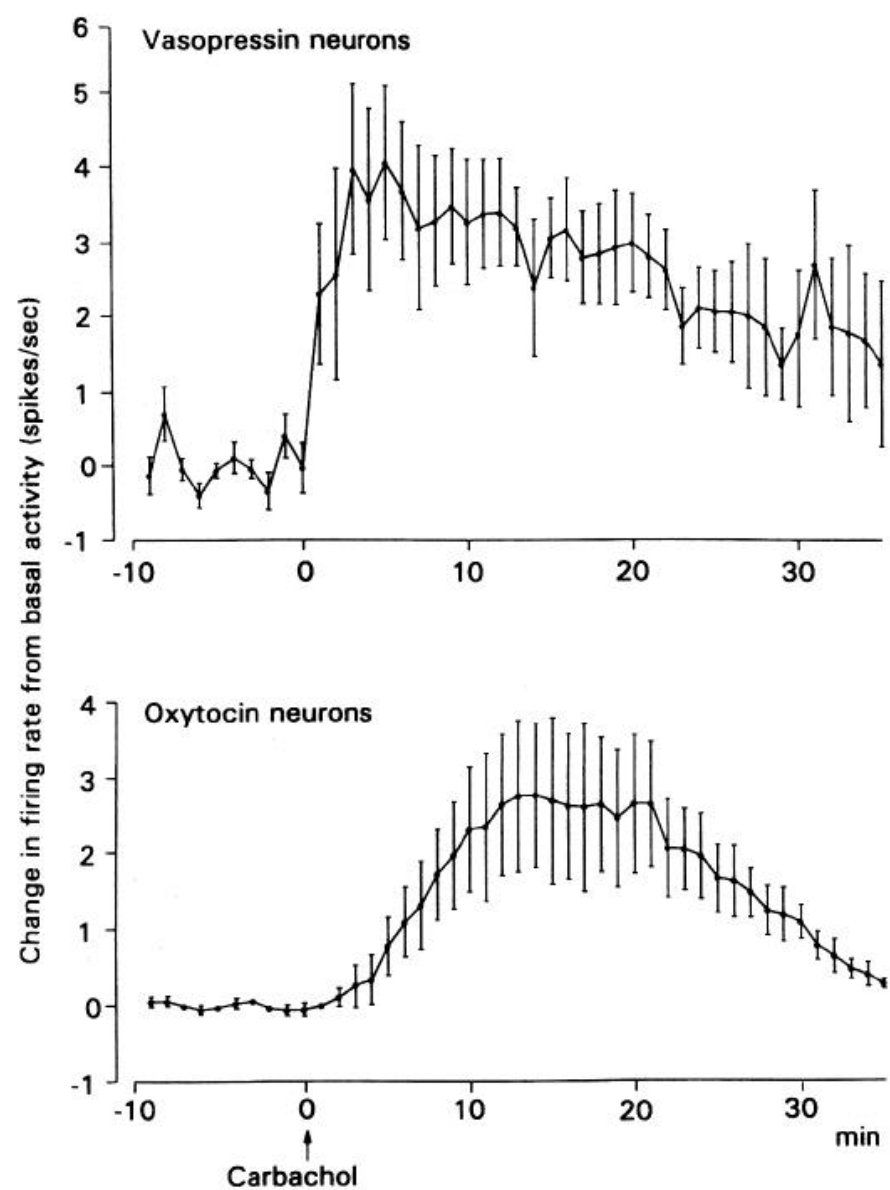

Figure 2. Population response of identified vasopressin and oxytocin neurons to intracerebroventricular carbachol. For each neuron the mean basal firing rate for the $10 \mathrm{~min}$ period before carbachol has been subtracted before individual data were meaned to give a population response. The vertical axis shows the change in spike activity from the basal rate. Vasopressin- (top) and oxytocinergic (bottom) supraoptic neurons.

ulating electrode was lowered onto the pituitary stalk and left in position for the same period of time, but no electrical stimulation was applied.

\section{Results}

\section{Effect of i.c.v. carbachol on electrical activity of supraoptic} neurons

The correct placement of the i.c.v. cannula was shown by a rise in intramammary pressure following administration of $0.2 \mu \mathrm{g}$ of carbachol (Fig. 1a). After an initial peak intramammary pressure sometimes showed fluctuations in intensity before declining over a period of about $20 \mathrm{~min}$.

Extracellular recordings were made from 10 supraoptic neurons; 6 identified as vasopressin neurons by their phasic firing pattern and lack of response to CCK and 4 oxytocin neurons, that responded to CCK with an excitation lasting for 5-15 min (Fig. 1b). Both vasopressin and oxytocin neurons responded to i.c.v. carbachol with an increase in firing, though oxytocin neurons took longer to reach a maximum rate. Vasopressin neurons increased in firing rate from an average basal level of approximately 5 spikes/sec to a maximum of $10 \mathrm{spikes} / \mathrm{sec}$ at $5 \mathrm{~min}$ (Fig. 2). Oxytocin neurons increased in firing from about 0.4 spikes/sec to a maximum of $3.2 \mathrm{spikes} / \mathrm{sec}$ at $13 \mathrm{~min}$ (Fig. 2). The firing rate of vasopressin and oxytocin neurons returned to baseline levels $30-40 \mathrm{~min}$ after carbachol administration.

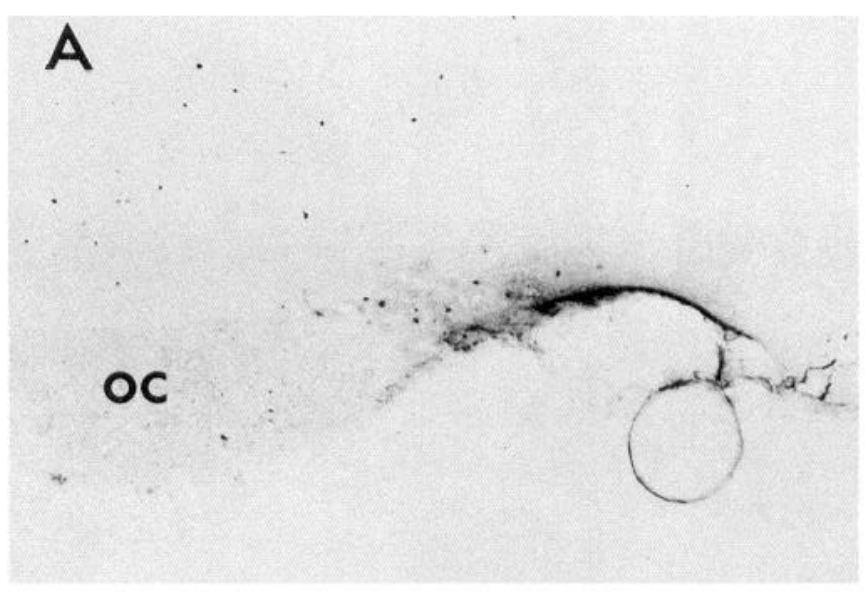

B

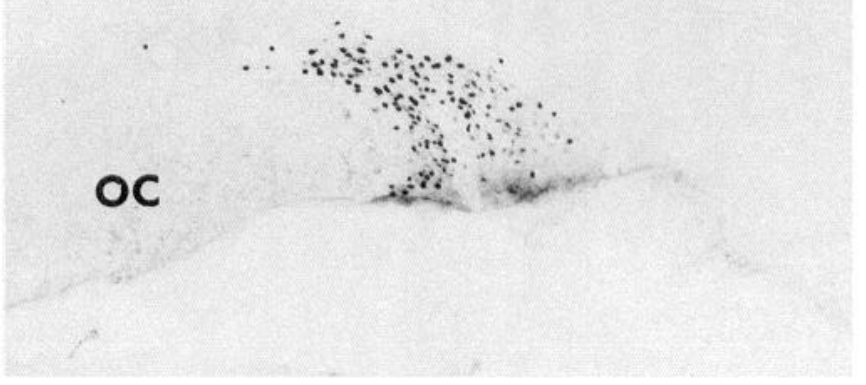

Figure 3. The induction of Fos-like immunoreactivity in the supraoptic nucleus following intracerebroventricular carbachol. The region of the supraoptic nucleus following an injection of $2 \mu \mathrm{l}$ of isotonic saline $(A)$ or $0.2 \mu \mathrm{g}$ of carbachol $(b) . O C=$ optic chiasm.

\section{Fos-like immunoreactivity following i.c.v. carbachol}

Coronal sections of the brain were examined from the level of the lamina terminalis caudally through the hypothalamus. In all brains, some Fos-LI nuclear profiles were seen in the cortex, septum, preoptic area and paraventricular nucleus of the thalamus. Often ependymal cells, normally on the side of injection, as well as cells of the choroid plexus and meninges contained Fos-LI. This staining was not related to the experimental grouping. There was a significant increase in the number of Fospositive profiles in the supraoptic nucleus (Fig. 3). Control animals had $19 \pm 4(n=5)$ positive profiles per section in the supraoptic nucleus and animals following i.c.v. carbachol had $78 \pm 16(n=6 ; P<0.02$; Fig. 4). The distribution of Fospositive cells through the supraoptic nucleus was homogeneous in both the ventrodorsal and the rostrocaudal orientation. Fospositive cells were seen in the paraventricular nucleus of the hypothalamus and the subfornical organ in both control and carbachol-treated groups, though no statistically significant differences were recorded in these structures. There were $104 \pm$ 38 and $109 \pm 38$ Fos-positive nuclear profiles/section in the paraventricular of control and carbachol-treated groups, respectively. For the subfornical organ, these figures were $26 \pm 9$ and $28 \pm 17$, respectively. 


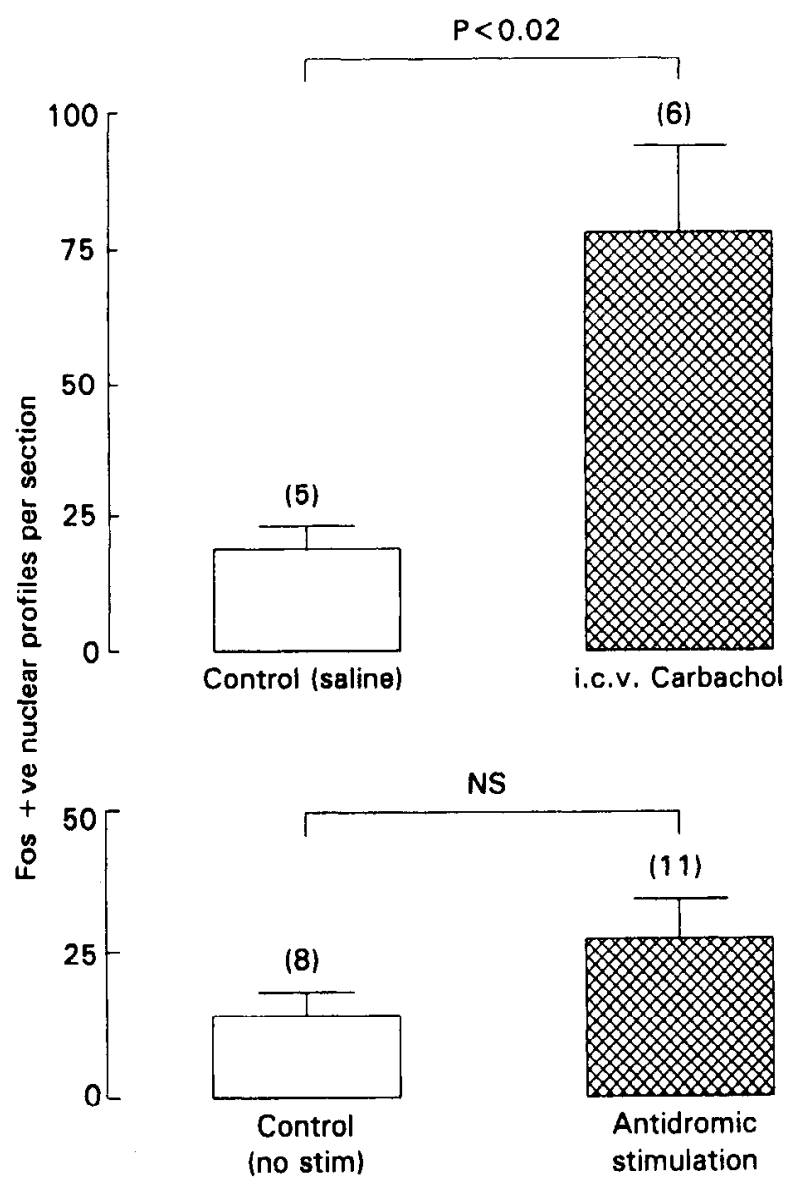

Figure 4. The effect of intracerebroventricular carbachol or antidromic stimulation on the Fos immunoreactivity in the supraoptic nucleus. Results are expressed as the number of Fos-positive nuclear profiles per section through the nucleus. The bars represent the mean and SE for each experimental group. The number of animals in each group is in parentheses. The panels show the effect of intracerebroventricular carbachol (top) and antidromic stimulation (bottom).

\section{Fos-like immunoreactivity following antidromic stimulation}

In those animals that were to receive antidromic stimulation correct placement of the stimulating electrode was verified by an intramammary pressure response to a short stimulus train. With the $15 \mathrm{~min}$ period of stimulation, intramammary pressure increased $10-15 \mathrm{sec}$ after the beginning of stimulation and remained high during the period of stimulation though it began to show oscillations most likely due to desensitization of oxytocin receptors in the mammary tissue (Fig. 5). Immediately following such stimulation the tissue does not respond to a bolus injection of oxytocin.

Animals in which the electrode was positioned but no stimulation given had a similar pattern of staining to that of brains injected with i.c.v. isotonic saline. Electrical stimulation of the pituitary stalk caused just under a doubling in the amount of Fos-LI in the hypothalamic supraoptic nucleus though the difference was not statistically significant (Fig. 4). The number of Fos-LI nuclear profiles per section in the supraoptic nucleus were $14 \pm 4(n=8)$ in the control group and $27 \pm 7(n=11)$ in the stimulated group. Similarly, there was no significant difference between groups in hypothalamic paraventricular nucleus (54 \pm 14 and $93 \pm 20$, respectively).

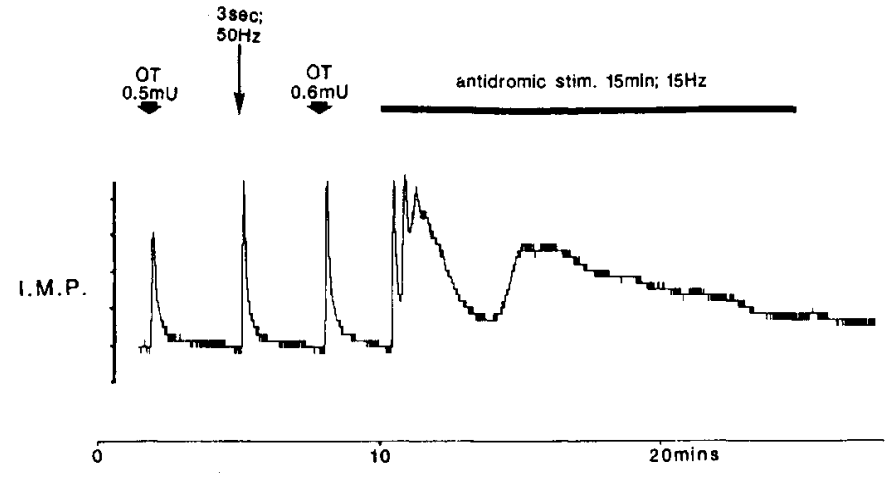

Figure 5. Intramammary pressure (I.M.P.) recording during antidromic stimulation. This is a typical I.M.P. trace to show the effectiveness of stimulation of the distal pituitary stalk. The I.M.P. is on an arbitrary scale. The sensitivity of the mammary gland was checked with intravenous injections of oxytocin $(O T ; 0.5$ and $0.6 \mathrm{mU})$ and the position of the stimulating electrode was then verified by applying a $3 \mathrm{sec}$ stimulation at $50 \mathrm{~Hz}$.

\section{Discussion}

The distribution of Fos-LI within the supraoptic nucleus following i.c.v. carbachol suggests that there is no selective activation of vasopressin over oxytocin neurons. This is borne out by the results of the electrophysiological experiments that extend the vasopressin.secretion assays and intramammary pressure rccordings prcviously made in intact animals (Clarke et al., 1978; Iitake et al., 1986). I.c.v. carbachol caused an approximate doubling in the firing rate of vasopressin neurons, which peaked at $6 \mathrm{~min}$. By comparison, the firing rate of oxytocin neurons was increased eightfold, though peak activity was not reached until $13 \mathrm{~min}$ after carbachol injection. In both neuronal types electrical activity returned to control values after $30-40 \mathrm{~min}$.

Supraoptic neurons have been shown to possess muscarinic receptors (Michels et al., 1986) and, using a slice preparation, Gribkoff et al. (1988) have shown a direct stimulatory effect of muscarinic receptor agonists on supraoptic neurons. The present results support a direct action of centrally administered carbachol on supraoptic neurons, though we cannot discount another indirect effect mediated by other structures, such as the subfornical organ (Mangiapane and Simpson, 1979). However, it should be noted that there was no increase in Fos- $\mathrm{LI}$ in the subfornical organ following carbachol. For the purposes of the experiment the precise site of action of carbachol is not important providing that ultimately there is an activation of postsynaptic receptors on the magnocellular neurons.

In the present experiments no differences were seen in the amount of Fos-LI in the hypothalamic paraventricular nucleus. Unlike the supraoptic nucleus, the paraventricular nucleus is a heterogeneous population and possesses many parvocellular neurons that do not project to the pituitary. These include oxytocin and vasopressin neurons, but also other cell types including those that contain corticotrophin releasing hormone. Fos-positive profiles in all experimental groups were often in parvocellular regions of the paraventricular nucleus. Although an increase in staining in the paraventricular nucleus might have been expected, without the use of retrograde tracing to distinguish magnocellular neurons, interpretation of this observation remains difficult.

Carbachol has been shown to stimulate DNA synthesis in a 
number of cell types via muscarinic receptors that are coupled to inositol phospholipid metabolism (Ashkenazi et al., 1989). The induction of c-fos in one cell line by carbachol is reduced if protein kinase $C$ is downregulated or if intracellular calcium is buffered (Trejo and Brown, 1991), showing the importance of these second messenger systems for Fos expression in this situation. Carbachol causes activation of magnocellular neurons by a receptor-mediated mechanism, either by a direct effect on the neurons themselves or indirectly via one or more afferent neurons. The subsequent induction of $c-f o s$ in supraoptic neurons by a direct effect of carbachol is likely to be mediated by phospholipid turnover, while indirect activation may involve this or other second messenger systems. Since a similar, but greater, number of antidromically propagated action potentials did not cause the same expression of Fos-LI, we can conclude that spike activity alone is not efficient at inducing Fos. In fact, although antidromic stimulation did not produce a statistically significant rise in the number of Fos-positive magnocellular neurons, there was some increase. This may be a consequence of the large calcium component of magnocellular neuron action potentials (Renaud, 1987), since an increase in intracellular calcium following membrane depolarization is capable of inducing c-fos in PC12 cells (Sheng et al., 1990). Therefore, the present results strongly suggest that transynaptic activation is required for the full induction of the immediate early gene, c-fos, under physiological conditions. In this context, it is interesting that PC 12 cells will only express c-fos in response to depolarization in the presence of protein kinase A activity (Ginty et al., 1991). The patterning of stimulation may be important and will need further investigation, though it should be noted that during lactation. when oxytocin neurons display patterning of discharge, there is no expression of immediate early genes.

The consequence of Fos induction in magnocellular neurons is still unclear. Fos forms heterodimers with members of the Jun family of immediate early genes, and these heterodimers bind to AP-1 binding domains in the promoter region of other genes to modulate transcription (Curran and Franza, 1988). Analysis of the rat oxytocin and vasopressin genes (Ivell and Richter, 1984) reveals that they each contain sequences in their promoter regions that differ from the canonical AP-1 site by just one base substitution (Leng et al., 1993b), though it is not yet known whether Fos/Jun complexes will bind to these sequences. However, enkephalin, dynorphin, and CCK (Sonnenberg and Rauscher, 1989; Naranjo et al., 1991; Monstein, 1993), which are colocalized with either vasopressin or oxytocin in magnocellular neurons (Zamir, 1985; Gaymann and Martin, 1987), all contain AP-1 binding sequences and may therefore be targets for Fos/Jun heterodimers.

Following parturition, salt-loading or CCK administration, oxytocin neurons express c-fos and c-jun (Hamamura et al., 1991, 1992; Verbalis et al., 1991; Luckman et al., 1993), but during lactation they express neither. Furthermore, although CCK administration is a strong stimulus for $c$-fos expression, it is only a weak stimulus for c-jun (M. Hamamura, personal communication). These stimuli, that are capable of activating oxytocin and vasopressin neurons either together or separately, involve different afferent pathways as well as various transmitters and second messenger systems (Leng et al., 1992; 1993a). The period or pattern of activation is set and modulated by synaptic input, but also by the intrinsic properties of the neuron (Renaud, 1987). The response of these neurons to different stimuli will require the activation of specific sets of genes which may be achieved, in part, by the differential induction of immediate early genes.

\section{References}

Ashkenazi A, Ramachandran J, Capon DJ (1989) Acetylcholine analogue stimulates DNA synthesis in brain-derived cells via specific muscarinic receptor subtypes. Nature 340:146-150.

Bourque CW (1989) Ionic basis for the intrinsic activity of rat supraoptic neurones by hyperosmotic stimuli. J Physiol (Lond) 417: 263-277.

Clarke G, Fall CHD, Lincoln DW, Merrick LP (1978) Effects of cholinoceptor antagonists on the suckling-induced and experimentally evoked release of oxytocin. Br J Pharmacol 63:519-527.

Curran T, Franza BR (1988) Fos and Jun: the AP-1 connection. Cell 55:395-397.

Fenelon VS, Poulain DA, Theodosis DT (1993) Oxytocin neuron activation and fos expression: a quantitative immunocylochemical analysis of the effect of lactation, parturition, osmotic and cardiovascular stimulation. Neuroscience 53:77-89.

Gaymann W, Martin R (1987) A re-examination of the localisation of immunoreactive dynorphin (1-8), [Leu] enkephalin and [Met] enkephalin in the rat neurohypophysis. Neuroscience 20:1069-1080.

Ginty DD, Glowacka D, Bader DS, Hidaka H, Wagner JA (1991) Induction of immediate early genes by $\mathrm{Ca}^{2+}$ influx requires cAMPdependent protein kinase in PC12 cells. J Biol Chem 266:1745417459.

Giovanelli L, Shiromani PJ, Jirikowski GF, Bloom FE (1990) Oxytocin neurons in the rat hypothalamus exhibit c-fos immunoreactivity upon osmotic stress. Brain Res 531:299-303.

Gribkoff VK, Christian EP, Robinson JH, Deadwyler SA, Dudek FE (1988) Cholinergic excitation of supraoptic neurons in hypothalamic slices of rat. Neuropharmacology 27:721-727.

Hamamura M, Leng G, Emson PC, Kiyama H (1991) Electrical activation and c-fos mRNA expression in rat neurosecretory neurones after systemic administration of cholecystokinin. J Physiol (Lond) 444:51-63.

Hamamura M, Nunez DJR, Leng G, Emson PC, Kiyama H (1992) $C$-fos may code for a common transcription factor within the hypothalamic neural circuits involved in osmoregulation. Brain Res $572: 42-51$.

Hoffman GE, Smith MS, Verbalis JG (1993) C-fos and related immediate early gene products as markers of activity in neuroendocrine systems. Front Neuroendocrinol 3:173-213.

Hughes P, Dragunow M (1993) Muscarinic receptor-mediated induction of Fos protein in rat brain. Neurosci Lett 150:122-126.

Hunt SP, Pini A, Evan G (1987) Induction of c-fos-like protein in spinal cord neurons following sensory stimulation. Nature $328: 632-$ 634.

Iitake K, Share L, Ouchi Y, Crofton JT, Brooks DP (1986) Central cholinergic control of vasopressin release in conscious rats. Am J Physiol 251:E146-E150.

Ivell R, Richter D (1984) Structure and comparison of the oxytocin and vasopressin genes from rat. Proc Natl Acad Sci USA 81:20062010.

Leng G, Way S, Dyball REJ (1991) Identification of oxytocin cells in the rat supraoptic nucleus by their response to cholecystokinin injection. Neurosci Lett 122:159-162.

Leng G, Dyball REJ, Luckman SM (1992) Mechanisms of vasopressin secretion. Horm Res 37:33-38.

Leng G, Luckman SM, Dyball REJ, Dye S, Hamamura M (1993a) Inputs from the nucleus tractus solitarii to the magnocellular neurosecretory system. Regul Pept 45:103-107.

Leng G, Luckman SM, Dyball REJ, Hamamura M (1993b) Induction of c-fos in magnocellular neurosecretory neurons. Ann NY Acad Sci 689:133-145.

Luckman SM (1992) Fos-like immunoreactivity in the brainstem of the rat following peripheral administration of cholecystokinin. J Neuroendocrinol 4:149-152.

Luckman SM, Antonijevic I, Leng G, Dye S, Douglas AJ, Russell JA, Bicknell RJ (1993) The maintenance of normal parturition in the rat requires neurohypophysial oxytocin. J Neuroendocrinol 5:7-12.

Mangiapane ML, Simpson JB (1979) Pharmacologic independence of subfornical organ receptors mediating drinking. Brain Res 178:507517. 
Michels KM, Meeker RB Hayward JN (1986) Differential distribution of muscarinic cholinergic and putative nicotinic cholinergic receptors within the hypothalamo-neurohypophysial system of the rat. Neuroendocrinology 44:498-507.

Monstein H-J (1993) Identification of an AP-1 transcription factor binding site within the human cholecystokinin (CCK) promoter. Neuroreport 4:195-197.

Morgan JI, Curran T (1991) Stimulus-transcription coupling in the nervous system: involvement of inducible proto-oncogenes fos and jun. Annu Rev Neurosci 14:421-451.

Naranjo JR, Mellstrom B, Achaval M, Sassone-Corsi P (1991) Molecular pathways of pain: Fos/Jun-mediated activation of a noncanonical AP-1 site in the prodynorphin gene. Neuron 6:607-617.

Paxinos G, Watson C (1986) The rat brain in stereotaxic coordinates, 2d ed. New York: Academic.

Poulain DA, Wakerley JB (1982) Electrophysiology of hypothalamic magnocellular neurosecretory neurones secreting oxytocin and vasopressin. Neuroscience 7:773-808.

Renaud LP (1987) Magnocellular neuroendocrine neurons: update on intrinsic properties, synaptic inputs and neuropharmacology. Trends Neurosci 10:498-502.

Renaud LP, Tang M, McCann MJ, Stricker EM, Verbalis JG (1987) Cholecystokinin and gastric distension activate oxytocinergic cells in the rat hypothalamus. Am J Physiol 253:R661-R665.

Sassone-Corsi P, Sisson JC, Verma IM (1988) Transcriptional autoregulation of the proto-oncogene fos. Nature 334:314-319.
Sharp FR, Sagar SM, Hicks K, Lowenstein D, Hisanaga K (1991) c-fos mRNA, Fos and Fos-related antigen induction by hypertonic saline and stress. J Neurosci 11:2321-2331.

Shen E, Dun SL, Ren C, Bennett-Clarke C, Dun NJ (1992) Hypotension preferentially induces c-fos immunoreactivity in supraoptic vasopressin neurons. Brain Res 593:136-139.

Sheng M, McFadden G, Greenberg ME (1990) Membrane depolarisation and calcium induce c-fos transcription via phosphorylation of transcription factor CREB. Neuron 4:571-582.

Shu S, Gong J, I ingzhi F (1988) The glucose oxidase-DAB-nickel method in peroxidase histochemistry of the nervous system. Neurosci Lett 85:169-171.

Sonnenberg JL, Rauscher FJ, Morgan JI, Curran T (1989) Regulation of proenkephalin by Fos and Jun. Science 246:1623-1625.

Trejo J, Brown J (1991) C-fos and c-jun are induced by muscarinic receptor activation of protein kinase $\mathrm{C}$ but are differentially regulated by intracellular calcium. J Biol Chem 366:7876-7882.

Verbalis JG, Stricker EM, Robinson AG, Hoffman GE (1991) Cholecystokinin activates $\mathrm{c}$-fos expression in hypothalamic oxytocin and corticotropin-releasing hormone neurons. J Neuroendocrinol 3:205213.

Zamir N (1985) On the origin of leu-enkephalin and met-enkephalin in the rat neurohypophysis. Endocrinology 117:1687-1692. 